\title{
THE NSW HEPATITIS C LOOKBACK PROJECT
}

Susanne Benjamin

Hepatitis Lookback Unit, NSW Blood Bank

This is article describes the NSW Hepatitis C Lookback Project, the aim of which is to identify recipients of blood products which were possibly contaminated with the hepatitis $\mathrm{C}$ virus (HCV), establish whether infection with HCV has ensued, and facilitate recipients' access to clinical and other services where appropriate.

The development of hepatitis in some patients a few months after transfusion has been a world-wide problem. Routine screening of blood donors for the hepatitis B antigen has been done in Australia since the early 1970s to ensure that blood from carriers is excluded from use. Despite this and the use of other exclusion criteria, the problem of posttransfusion hepatitis has persisted.

Before 1990 these cases of "serum" hepatitis were categorised as non-A, non-B hepatitis. In the late 1980s the hepatitis $\mathrm{C}$ virus was discovered and a serological test was subsequently developed to detect evidence of the virus. HCV is recognised to be the predominant cause of non- $\mathrm{A}$, non- $\mathrm{B}$ hepatitis, and the infection which results is referred to as hepatitis $\mathrm{C}^{1}$. Since acute hepatitis $\mathrm{C}$ is usually subclinical, it is difficult to determine accurately when infection occurred. Thus, when a blood donor is identified as HCV positive, every component donated should be treated as potentially infectious. Since the introduction of hepatitis $\mathrm{C}$ antibody screening of all blood donations, clinical post-transfusion hepatitis has been virtually eliminated in Australia.

\section{DEFINING "LOOKBACK"}

"Lookback" is the process of tracing blood products released by a blood bank for normal use. The term is often associated with tracing components suspected to have been contaminated with an infectious agent. Where a component has been transfused, a "lookback" investigation includes identification of the recipient and testing for evidence of infection. Identification of people with transfusion-acquired infection is important to ensure they receive clinical management and counselling. It is an onerous task, limited by the accuracy of records and changes which occur with the passage of time.

\section{HePATITIS C LOOKBACK IN NSW}

Serological testing for HCV began in NSW in February 1990. With its introduction, a number of routine blood donors were identified as hepatitis C positive and lookback was initiated on some components for hepatitis C. Until recently the extent of this process was limited. After prolonged discussions by State and Commonwealth health authorities, it was agreed late in 1995 that an extended donor-triggered HCV lookback should proceed nationwide. In NSW this is being undertaken as a joint endeavour of the NSW Red Cross Blood Transfusion Service (BTS) and NSW Health Department's AIDS/Infectious Diseases Branch.

The project, which is managed by the Hepatitis Lookback Unit at the BTS, was designed to review all donations made by HCV positive donors, in all 28 Blood Banks in NSW, as far back as 1983. An HCV positive donor is defined as a blood donor who has tested both anti-HCV antibody positive by enzyme-linked immunosorbent assay (EIA) and immunoblot. The database of donors requiring Lookback is yet to be finalised. Estimates suggest there will be more than 800 donors in the cohort.

\section{KEY POINTS - HEPATITIS C LOOKBACK}

ㅁ. Acute hepatitis $\mathrm{C}$ infection is usually subclinical. Before the discovery of the hepatitis $\mathrm{C}$ virus and the advent of serological screening to detect its presence, it was possible for a person with hepatitis $\mathrm{C}$ to be a hidden infection risk and donate blood.

- HCV is recognised as the major cause of posttransfusion non-A non-B hepatitis.

- Since the introduction of hepatitis $\mathrm{C}$ antibody screening of all blood donations, clinical posttransfusion hepatitis has been virtually eliminated in Australia.

- The Hepatitis C Lookback Project aims to identify recipients of blood contaminated with the hepatitis $\mathrm{C}$ virus and facilitate access to appropriate counselling and medical advice.

Information on the fate of implicated blood products is to be gathered from institutions to which blood was dispatched. Where a product was transfused, the Hepatitis Lookback Unit will trace recipients and screen them for evidence of $\mathrm{HCV}$. It is planned that clinical activities including recipient testing, ongoing care such as specialist referral, follow-up testing, and testing of intimate contacts, will be managed by the recipient's family doctor. Due to the difficulties in establishing a diagnosis and the low risk of transmission to close contacts, no further tracing will be done if a recipient is deceased.

\section{WHAT IS THE HEPATITIS C LOOKBACK TRYING TO ACHIEVE?}

Hepatitis $\mathrm{C}$ causes inflammation of the liver and can be transmitted via blood and other body fluids. The striking feature of HCV is its ability to persist in the host, and studies indicate it is a disease with a long latency, with the mean interval for exposure to onset of symptoms being 13 years. Chronic hepatitis occurs in the majority ( $>70$ per cent) of people infected by $\mathrm{HCV}^{3}$. After several years some of those with persistent infection develop liver failure and/or hepatocellular carcinoma ${ }^{4}$.

Given the insidious nature of chronic hepatitis $\mathrm{C}$ infection, the Australian Red Cross believes it has a public health duty to identify people who have acquired hepatitis $\mathrm{C}$ infection from transfusion, to ensure they have every opportunity to receive appropriate care. Early access to medical treatment and counselling is likely to reduce the risk of transmission of the virus and provide the opportunity possibly to minimise long-term effects of chronic infection.

Recipients will learn about HCV and the Lookback Project from their general practitioner (GP). It is acknowledged that GPs are likely to have limited detailed knowledge about the virus, so the Hepatitis C Lookback Unit will distribute information to these doctors at the time of testing and provide additional resources as required. Information provided routinely will include brochures from the Hepatitis C Council and the Transfusion Related AIDS and Infectious Diseases Unit (TRAIDS). The Hepatitis C Council offers a general Information and Support Line service to the wider community, and TRAIDS has a specific responsibility to offer crisis counselling and long-term 


\section{FIGURE 1}

\section{LOOKBACK PROCESS}

This flow diagram illustrates the process of tracing a component suspected to have been contaminated with an infectious agent. In the case of the Hepatitis Lookback Project the agent is the hepatitis C virus.

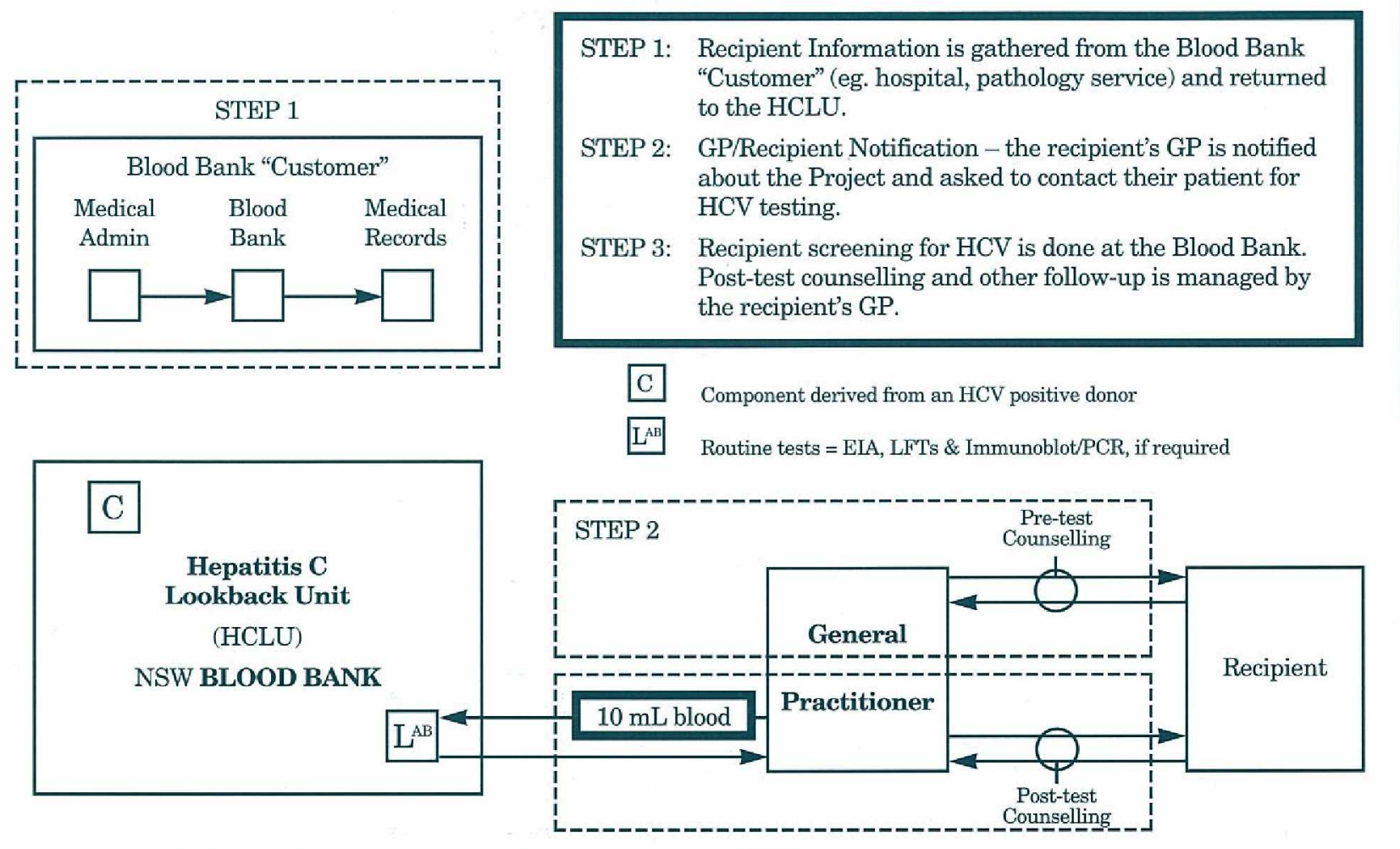

counselling to clients who have acquired an infection through a medical procedure.

More information on the Hepatitis C Lookback Project may be obtained from Dr Susanne Benjamin, Hepatitis Lookback Unit, NSW Blood Bank, on (02) 92294349 or (02) 92294444.

The Blood Bank thanks all those who have assisted in this and other Lookback work.

1. Ismay SL, Thomas S, Fellows A, Keller A, Kenrick KG, Archer GT, Wylie BR, Cossart Y. Post-transfusion hepatitis revisited. Med J Aust 1995; 163:74-77.

2. Alter HJ. To C or not to C: these are the questions. Blood 1995; 85(7):1681-1695.

3. Tong MJ, NS El-Farra, Reikes AR, Co RL. Clinical Outcomes after Transfusion Associated Hepatitis C. New Engl J Med 1995; 332:14631466.

4. Alter HJ, Purcell RH, Shih JW et al. Detection of antibody to hepatitis $\mathrm{C}$ virus in prospectively followed recipients with acute and chronic non-A non-B hepatitis. New Engl J Med 1989; 321:1494-1500.

\section{PUBLIC HEALTH EDITORIAL STAFF}

The editor of the NSW Public Health Bulletin is Dr Michael Frommer, Director, Centre for Research and Development, NSW Health Department. Dr Lynne Madden is production manager.

The Bulletin aims to provide its readers with population health data and information to motivate effective public health action. Articles, news and comments should be 1,000 words or less in length and include a summary of the key points to be made in the first paragraph. References should be set out using the Vancouver style, the full text of which can be found in British Medical Journal 1988; 296:401-5.

Please submit items in hard copy and on diskette, preferably using WordPerfect, to the editor, NSW Public Health Bulletin, Locked Mail Bag 961, North Sydney 2059. Facsimile (02) 93919029.

Please contact your local Public Health Unit to obtain copies of the NSW Public Health Bulletin. The Bulletin can be accessed via the Internet from the NSW Health Department's World Wide Website, at http://www.health.nsw.gov.au/public-health/phb/phb.html Back issues can be obtained from the Better Health Centre, Locked Mail Bag 961, North Sydney 2059. Telephone: (02) 9954 1193, Facsimile (02) 99555196. 